ASTHMA

\title{
Psychological factors and asthma quality of life: a population based study
}

\section{R J Adams, D H Wilson, A W Taylor, A Daly, E Tursan d'Espaignet, E Dal Grande, R E Ruffin}

See end of article for authors' affiliations

.....................

Correspondence to: Dr R J Adams, Department of Medicine, The Queen Elizabeth Hospital, Woodville, South Australia 5011, Australia; robert. adams@nwahs.sa.gov.au

Received 12 May 2003 Accepted 25 January 2004
Background: Reports of psychological conditions in asthmatic subjects have been limited to certain population groups or convenience samples. A study was undertaken of the prevalence of psychological distress in asthma in the general population and its associations with quality of life.

Methods: The WANTS Health and Well-being Survey is a population household interview survey of adults lage $\geqslant 18$ ) in Western Australia, the Northern Territory, and South Australia. Data obtained were weighted to the closest census data to provide population representative estimates. Positive answers to two questions: "Have you ever been told by a doctor that you have asthma?" and "Do you still have asthma?" determined current doctor-diagnosed asthma. Other items included the SF-12, the Kessler-10 index of psychological distress, questions on feelings of lack of control in different areas of life, and on mental health conditions.

Results: From the available sample of 10080,7619 interviews were completed (participation rate $74.8 \%$ ), with 834 people reporting current doctor-diagnosed asthma (11.2\%). Psychological distress was more frequent in those with asthma $(17.9 \% v 12.2 \%, \mathrm{p}<0.01)$ and a higher proportion with asthma were at higher risk for anxiety or depression $(40.5 \% \vee 31.2 \%, \mathrm{p}<0.01)$. Mental health conditions were also more common $(16.2 \% \vee 10.8 \%, p<0.01)$, as was the frequency of those who sometimes or always felt a lack of control over their health $(33.5 \% \vee 24.3 \%, p<0.01)$. People with both asthma and psychological distress had significantly lower scores on the SF-12 physical component summary (PCS) than those with either asthma or distress alone. Among those with psychological distress, mental component summary (MCS) scores did not differ between asthmatic and non-asthmatic respondents. In a multiple regression model the frequency of a feeling of lack of control over health-together with age, family's financial situation, education level, and number of days partially unable to work or perform usual duties-was significantly associated with scores on the PCS ( $r=0.73$, adjusted $\left.r^{2}=0.54\right)$.

Conclusion: These results, from a representative population sample, show that psychological distress and decreased feelings of control are common in asthma and are significantly associated with physical health status. l chronic illnesses, health status and quality of life are often better correlated with psychosocial factors than physical disease severity. ${ }^{1}$ In asthma this issue is complex as disease severity is assessed indirectly and disease manifestations are partly dependent on individual behaviour such as adherence to medication and trigger avoidance. ${ }^{2}$

People with asthma and comorbid psychiatric disorders have been reported to have poorer asthma control and higher healthcare utilisation. ${ }^{3}{ }^{4}$ Studies on near-fatal asthma have shown high levels of denial with a high index of psychiatric caseness in these patients. ${ }^{5}$ Kolbe et $a l^{6}$ reported that up to $56 \%$ of patients with severe asthma have severe anxiety and $19 \%$ have depression. Others have shown that the prevalence of depression, anxiety and emotional disorders in hospital clinic samples is higher than in controls. ${ }^{38}$

Many of the studies that have investigated this association have been drawn from clinic or convenience samples, limiting conclusions that may be drawn about the generalisability of the results. ${ }^{378}$ By contrast, in a population sample Janson et al did not find any evidence that those with diagnosed asthma had more anxiety or depression than those without asthma. ${ }^{9}$ It is likely that different sampling frames account for the discrepancies noted here. At the more severe end of the asthma spectrum, it appears that emotional disorders are common. However, it remains unclear what the prevalence of psychological distress is in the general asthma population.
The impact of psychological distress on the health of the population with asthma is also not well described. Hospital admissions $^{3}$ and re-admissions for asthma seem to be higher in people with anxiety or pessimism. ${ }^{10}$ In a small sample of 50 people identified specifically with asthma in the Medical Outcomes Study, asthma was associated with significant negative effects on the Mental Health Component Summary of the SF-36. ${ }^{11}$ However, Afari et al did not find anxiety and depression to be related to asthma severity in adults. ${ }^{4}$ On a population basis, it is unclear whether psychosocial distress exerts an impact on physical health in people with asthma.

A large body of evidence in health promotion documents the crucial role played by individuals having a sense of responsibility and control over health behaviours. ${ }^{12}$ Many intrapersonal theories of health behaviour share an emphasis on perceived self-control or self-efficacy. ${ }^{13}$ A necessary first step in behaviour modification is an individual's belief that personal action can have a positive effect on any given circumstance. ${ }^{13}$ In terms of asthma, this translates into a belief that the illness can be controlled by self-management. ${ }^{12}$ However, no association between health locus of control and treatment adherence with asthma medications has been found consistently by researchers. ${ }^{14}{ }^{15}$ Katz et al found that, in a largely female, well educated population recruited following specialist outpatient visits, perceived control was associated with asthma outcomes, including quality of life. ${ }^{16}$ The 
extent to which feelings of a lack of control can affect quality of life is not well known at a population level.

A study was undertaken to examine whether mental health conditions and psychological distress were more common in people with asthma and to assess the impact of psychological conditions and perceived self-control on their quality of life. We used data from the Health and Well-being Survey (WANTS study), a large population survey of wellbeing in adults living in Western Australia (WA), the Northern Territory (NT) and South Australia (SA).

\section{METHODS}

\section{Study population}

All households in SA, WA, and NT with a telephone connected and the number listed in the current version of the electronic white pages were eligible for selection in the sample. Samples were drawn separately for each state. The target number of interviews for each state was 2500. A stratified sampling technique was used with the distribution of these interviews planned as $\mathrm{n}=900$ in the metropolitan area, $n=800$ in rural areas, and $n=800$ in remote areas. The minimum sample size of $\mathrm{n}=800$ was necessary to enable population estimates to be made with reasonable confidence intervals for the less populated areas of each state. This was particularly so in the rural and remote areas of SA and WA where a random sample of each state would have resulted in a small number of respondents for these areas. As a consequence of the need to over-sample non-metropolitan areas, separate samples were drawn for each of the three geographical regions (metro/rural/remote) for each of the states. These samples represented increasing proportions of the population as remoteness increased. The definitions of remoteness were based on Australian Bureau of Statistics Accessibility/Remoteness Index of Australia (ARIA) codes. ${ }^{17}$

\section{Survey method}

Within each household the person aged 18 years or over who had their birthday last was selected for interview. There was no replacement for non-contactable persons or refusals. An introductory letter was sent to each selected household from the health department of each state. Interviews were conducted during November/December 2000 by trained health interviewers using the Computer Assisted Telephone Interview (CATI III) system, with at least six callbacks as needed.

\section{Survey items}

Current doctor diagnosed asthma was determined by positive responses to two questions asking participants ( 1 ) if they had ever been told by a doctor they had asthma and (2) if they still had asthma. No data on clinical asthma variables were available.

The Kessler Psychological Distress Scale (K10) was developed for screening populations to yield a "global measure of psychological distress". ${ }^{18} 19$ The scale consists of 10 questions on non-specific psychological distress and is about the level of anxiety and depressive symptoms a person may have experienced in the most recent 4 week period. From US national population survey data Kessler and Mroczek determined that the 10 -item set represented the "entire range of high distress" and were "highly discriminating along that continuum". ${ }^{18} 20$ Andrews and Slade have produced normative Australian data on the K10 using the National Survey of Mental Health and Well-being survey data conducted in 1997. ${ }^{21}$

Quality of life was measured using the SF- $12,{ }^{22}$ which is a subset of the SF-36 and is a valid measure of health status in Australia. ${ }^{23}$ Respondents were also asked about perceived level of lack of control in six areas of their life including health, financial situation, personal life, job security, work life, and in general. Respondents were asked if they had ever been told by a doctor in the last 12 months that they had anxiety, depression, stress related problem, or any other mental health problem. Those who responded positively were asked if they still have this condition and if they were currently receiving treatment for the condition. Other items included questions on demographics and healthcare utilisation.

\section{Statistical analysis}

Data were analysed using the SPSS version 11.0. Differences in proportions were assessed for significance by $\chi^{2}$ tests and Mantel-Haenszel methods for analysis of $2 \times k$ tables. The test for linear trend was used to determine the statistical significance of psychological distress, mental health, and level of lack of control according to asthma status. The data were weighted by age, sex, and probability of selection in the household ${ }^{24}$ using the Australian Bureau of Statistics population estimates for 1999 so that the health estimates calculated would be representative of the adult population. This resulted in occasional minor rounding effects for the numbers.

The SF-12 was scored as specified in the SF-12 scoring manual. ${ }^{25}$ We present the results of the items aggregated into the physical component summary (PCS) and the mental component summary (MCS) scales. $^{25}$ These scores are constructed so that the mean for the general population is set at 50 with a standard deviation of 10, and higher scores indicate better quality of life. SF-12 scores whether PCS is less in people with asthma and psychosocial distress than in either category alone. Using MANOVA analysis, controlling for age and sex, we examined the effects of asthma, psychological distress, and the two together on SF-12 scores. Significance tests are reported for the interaction term for the effects of both variables together in addition to the main effects of each separately on PCS and MCS scores. The tables show the actual scores obtained from the analyses.

The $\mathrm{KlO}$ is scored in a summative manner with a possible range of scores from 10 to 50 where 50 indicates a high risk of anxiety or depressive disorder. ${ }^{19}{ }^{21}$ There are two different documented methods for interpreting K10 scores. The

Table 1 Proportions in different demographic categories among those with and without a current asthma diagnosis

\begin{tabular}{lcc} 
& $\begin{array}{c}\text { Asthma } \\
(\mathbf{n}=834)\end{array}$ & $\begin{array}{c}\text { No asthma } \\
(\mathbf{n}=6609)\end{array}$ \\
\hline Sex & & \\
Male & 40.9 & $52.2^{*}$ \\
Age (years) & 21.7 & $12.4^{*}$ \\
18-24 & 41.8 & 44.3 \\
$25-44$ & 24.3 & 30.2 \\
$45-64$ & 12.1 & 13.1 \\
$65+$ & 4.6 & 4.7 \\
Education & 54.3 & 54.4 \\
Primary school & 16.2 & 20.5 \\
Secondary/high school & 23.7 & 19.9 \\
Trade/apprenticeship/certificate & & \\
University degree & 2.3 & 2.6 \\
Work status & 31.9 & 30.3 \\
Unemployed & 19.9 & 17.1 \\
Retired/student/home duties & 45.9 & 49.9 \\
Part time & & \\
Full time & 18.0 & 16.9 \\
Income & 15.3 & 15.6 \\
$\quad \$ 20$ 000 & 33.5 & 34.2 \\
$>\$ 20000-40$ 000 & 14.6 & 20.3 \\
$>\$ 40000-80$ 000 & 47.9 & 44.4 \\
\hline \$80 000 & & \\
Department of Social Security pension & & \\
\hline * $<0.01$. & & \\
&
\end{tabular}


Clinical Research Unit for Anxiety and Depression (CRUFAD), School of Psychiatry, University of NSW has developed cut-off scores for the K10 by comparing the scores against the CIDI instrument. ${ }^{19}$ Scores of 10-15 indicate low or no risk, 16-29 indicates medium risk, and 30-50 indicates a high risk of anxiety or depressive disorder. ${ }^{19} 21$ Alternatively, standardised scores can be derived by converting the raw scores to a " $t$ score" by subtracting the mean of the score and dividing by the standard deviation of the score. Scores are then standardised with a mean of 50 and a standard deviation of 10. Psychological distress is determined by taking one standard deviation above the mean minus $60 .{ }^{20} \mathrm{In}$ this analysis data will be presented using both scoring methods.

Multiple linear regression was used to develop models for the SF-12 PCS for people reporting current doctor-diagnosed asthma. Variables significant at $\mathrm{p}<0.10$ in bivariate analyses were candidates for inclusion in the multivariate models. A forward stepwise linear regression technique was used to obtain the best joint predictors of SF-12 PCS scores. An initial base model including age, education, and financial situation was developed. We then tested variables of control and psychological distress to assess if any further variance in PCS scores could be associated with these variables. For the logistic regression analysis feelings of lack of control over health were categorised as always/often, sometimes, rarely/ never. Education level was categorised as high school only, trade/apprenticeship/certificate, university/college. Days partly unable to work or perform usual activities in the past 4 weeks were grouped into $0,1-5$ or $>5$ days. Conditioning of the model and cross correlations were assessed to check model fit.

\section{RESULTS}

The demographic characteristics of subjects with and without asthma are shown in table 1 . Those with asthma were significantly more likely to be female and aged $18-24$ years $(p<0.01)$. There were no statistically significant differences in the proportion reporting current asthma between states or between metropolitan, rural or remote regions. However, the prevalence of current asthma standardised by age and sex to the 1991 census indicated a significant difference between South Australia and Northern Territory (13.2\% v 10.1\%, $\chi^{2}$ test, $\mathrm{p}<0.05$ ).

The frequency of self-reported mental health conditions of any type diagnosed over the past 12 months was significantly more common in people with asthma. The proportion with psychological distress and at high or medium risk for anxiety or depressive disorders was also significantly more common in asthmatic subjects (table 2). These subjects were significantly more likely to report always or often feeling a lack

Table 2 Proportion (\%) with psychological distress and diagnosed mental health conditions in subjects with and without a diagnosis of asthma

\begin{tabular}{|c|c|c|}
\hline & $\begin{array}{l}\text { Asthma } \\
(n=834)\end{array}$ & $\begin{array}{l}\text { No asthma } \\
(\mathrm{n}=6609)\end{array}$ \\
\hline \multicolumn{3}{|l|}{ Kessler 10 (NSW scoring) } \\
\hline Psychological distress* & 17.9 & 12.2 \\
\hline \multicolumn{3}{|l|}{ Kessler 10 (U of NSW scoring)* } \\
\hline 30-50 (high risk) & 3.6 & 2.7 \\
\hline 16-29 (medium risk) & 36.9 & 28.5 \\
\hline 12-15 (low risk) & 59.5 & 68.9 \\
\hline \multicolumn{3}{|l|}{ Mental health condition } \\
\hline Diagnosed in last 12 months* & 16.2 & 10.8 \\
\hline Still have a diagnosed condition* & 12.7 & 7.6 \\
\hline Currently receiving treatment ${ }^{\star}$ & 1.3 & 0.5 \\
\hline
\end{tabular}

Table 3 Proportions with different levels of feeling of lack of control in general, over health, finances, and personal life in subjects with and without a diagnosis of asthma

\begin{tabular}{|c|c|c|}
\hline & $\begin{array}{l}\text { Asthma } \\
(n=834)\end{array}$ & $\begin{array}{l}\text { No asthma } \\
(n=6609)\end{array}$ \\
\hline \multicolumn{3}{|c|}{ Lack of control-in general ${ }^{*}$} \\
\hline Always/often & 7.1 & 4.8 \\
\hline Sometimes & 19.2 & 16.6 \\
\hline Rarely/never & 73.7 & 78.5 \\
\hline \multicolumn{3}{|c|}{ Lack of control-health* } \\
\hline Always/often & 11.7 & 6.6 \\
\hline Sometimes & 21.8 & 17.7 \\
\hline Rarely/never & 67.5 & 75.7 \\
\hline \multicolumn{3}{|c|}{ Lack of control-finances* } \\
\hline Always/often & 17.4 & 11.2 \\
\hline Sometimes & 21.9 & 21.7 \\
\hline Rarely/never & 59.7 & 67.1 \\
\hline \multicolumn{3}{|c|}{ Lack of control-personal life* } \\
\hline Always/often & 6.3 & 4.1 \\
\hline Sometimes & 18.7 & 15.9 \\
\hline Rarely/never & 74.9 & 80.0 \\
\hline \multicolumn{3}{|c|}{ Lack of control-job security } \\
\hline Always/often & 9.1 & 6.4 \\
\hline Sometimes & 12.8 & 12.2 \\
\hline Rarely/never & 78.1 & 81.3 \\
\hline \multicolumn{3}{|c|}{ Lack of control-work life } \\
\hline Always/often & 6.5 & 5.7 \\
\hline Sometimes & 13.8 & 15.3 \\
\hline Rarely/never & 79.7 & 79.0 \\
\hline
\end{tabular}

of control over their life in the areas of health, finances, personal life and in general (table 3). No statistically significant differences were found in terms of job security and work life for feelings of control.

Asthma had an adverse impact on quality of life on both physical (PCS 47.6 (10.9) $v 50.2$ (9.1), p<0.01) and mental health (MCS 50.9 (9.6) v 52.2 (8.8), p<0.05) component summary scales. Psychological distress and diagnosed mental health conditions affected quality of life in both physical and mental health domains. People with asthma who also reported psychological distress or a mental health condition had significantly lower scores on the PCS than those with either asthma or psychological conditions alone (table 4). Among those with psychological distress, MCS scores did not differ between asthmatic and non-asthmatic respondents. The relationships seen between quality of life scores and psychological distress were not significantly affected when scores were adjusted for age and sex.

Those with asthma who reported always or often having a feeling of lack of control over their health and life in general had statistically and clinically significant ${ }^{11}$ decrements in PCS scores compared with those without asthma who reported a lack of control in these areas. No differences were seen in MCS scores between those with and without asthma at similar levels of feelings of lack of control (table 5).

In a multiple regression model among subjects with current doctor-diagnosed asthma, in addition to demographic variables (age, education level, family's financial situation), the number of days partially unable to work or perform usual duties and the frequency of a feeling of a lack of control over health were significantly associated with PCS scores $\left(r=0.73\right.$, adjusted $r^{2}=0.54$, table 6$)$.

\section{DISCUSSION}

In a representative population survey psychological distress was significantly more frequent in subjects with asthma and a higher proportion with asthma were at greater risk for anxiety or depression. Diagnosed mental health conditions were also significantly more common, as was the frequency 
Table 4 Mean (SD) SF-12 physical component summary (PCS) score and mental component summary (MCS) score and measures of mental health in those with and without asthma

\begin{tabular}{|c|c|c|c|c|}
\hline \multirow[b]{2}{*}{ Mental health variable (asthma:no asthma) } & \multicolumn{2}{|l|}{ PCS } & \multicolumn{2}{|l|}{ MCS $\ddagger$} \\
\hline & Asthma & No asthma & Asthma & No asthma \\
\hline \multicolumn{5}{|l|}{ Kessler 10§ (NSW scoring) } \\
\hline Psychological distress (151:781) & $40.6(14.1)^{*}$ & 44.9 (13.2) & $37.8(10.9)$ & $37.8(10.8)$ \\
\hline No distress (702:5812) & $47.6(10.6)$ & $50.4(8.7)$ & $53.7(7.0)$ & $54.2(6.5)$ \\
\hline \multicolumn{5}{|l|}{ Kessler 10 } \\
\hline $30-50$ (high risk) (30:176) & $36.6(13.5)^{\star}$ & $43.1(14.7)$ & $30.3(10.2)$ & $30.4(9.7)$ \\
\hline 16-29 (medium) (308:1883) & $45.6(12.1)$ & 47.9 (11.3) & $46.0(9.9)$ & $46.0(9.5)$ \\
\hline 12-15 (low) (496:4551) & $49.6(9.1)$ & $51.5(7.5)$ & $55.1(5.5)$ & $55.6(5.0)$ \\
\hline \multicolumn{5}{|l|}{ Mental health condition } \\
\hline Current diagnosed (146:751) & $43.0(12.1) \dagger$ & $47.5(11.5)$ & $42.8(11.7)$ & $42.9(11.4)$ \\
\hline No (687:5858) & $48.6(10.3)$ & $50.6(8.8)$ & $52.6(8.1)$ & $53.4(7.6)$ \\
\hline \multicolumn{5}{|l|}{ Mental health condition } \\
\hline Diagnosed in last 12 months (145:724) & $41.8(12.6)^{*}$ & $47.1(11.6)$ & $41.3(12.3)$ & $42.6(11.6)$ \\
\hline On treatment $(12: 50)$ & $38.3(13.0)^{*}$ & $49.0(10.2)$ & $45.8(11.4)$ & $47.0(11.2)$ \\
\hline No $(696: 5819)$ & $46.9(11.1)$ & $50.1(9.1)$ & $53.0(8.0)$ & $53.5(7.7)$ \\
\hline $\begin{array}{l}{ }^{*} p<0.01 ; \uparrow p<0.05 \text {. } \\
\text { fHigher scores indicate better quality of life. } \\
\text { SNSW Health scoring. } \\
\text {-University of NSW scoring. }\end{array}$ & & & & \\
\hline
\end{tabular}

of those who sometimes or always felt a lack of control over their health, finances, and life in general. People with asthma and psychological distress had significantly lower scores on the SF-12 PCS than those with either asthma or psychological distress alone. In those with psychological distress, MCS scores did not differ between asthmatic and non-asthmatic respondents. The level of perceived control over health was significantly associated with scores on the PCS in a multivariate model. This model was able to account for over half of the variance in scores without inclusion of any clinical asthma variables which were unavailable in this dataset.

Psychological factors may influence asthma management in a number of ways. Depression is associated with decreased performance on problem solving, ${ }^{26}$ complex task performance, ${ }^{27}$ memory, ${ }^{28}$ and attention span. ${ }^{29}$ All of these cognitive processes can influence the decision making and effectiveness of self-management of people with asthma. Decision making during attacks of slow onset asthma has been shown to be suboptimal, even when theoretical knowledge of appropriate action has been adequate. ${ }^{30}$ Anxiety can also adversely affect asthma by influencing self-management behaviour and by effects on the autonomic and immune systems. $^{31}$ In contrast, very low levels of disease-specific anxiety may lead to increased asthma morbidity as anxiety may be needed to motivate individuals to initiate treatment. ${ }^{32}$

Our findings of an association between feelings of control and quality of life are similar to those of Katz et al ${ }^{16}$ who used an asthma specific scale in a specialist clinic population. Individuals who actively seek out information and solutions to health problems have been found to have better health outcomes in a number of illnesses. ${ }^{33}$ Interventions that teach the necessary skills and encourage patients to negotiate

Table 5 Mean (SD) SF-12 physical component summary (PCS) score and mental component summary (MCS) score and frequency of feelings of lack of control in those with and without asthma

\begin{tabular}{|c|c|c|c|c|}
\hline \multirow[b]{2}{*}{ Mental health variable (asthma:no asthma) } & \multicolumn{2}{|l|}{ PCS } & \multicolumn{2}{|l|}{ MCS $\ddagger$} \\
\hline & Asthma & No asthma & Asthma & No asthma \\
\hline \multicolumn{5}{|l|}{ Lack of control-in general } \\
\hline Always (16:101) & $31.9(12.0)^{*}$ & $46.8(12.1)$ & $41.5(15.2)$ & 40.0 (14.4) \\
\hline Often (53:234) & $42.4(13.7)^{\star}$ & 47.5 (12.7) & 41.7 (12.0) & 40.0 (12.2) \\
\hline Sometimes (166:1036) & $45.6(12.3) \dagger$ & 49.1 (10.8) & $45.9(10.0)$ & $46.1(10.3)$ \\
\hline Rarely (161:1264) & $47.5(10.6)$ & $50.2(8.9)$ & $50.8(9.0)$ & $51.4(7.7)$ \\
\hline Never (457:3958) & $46.3(10.9) \dagger$ & $50.0(9.0)$ & $54.1(7.9)$ & $55.2(6.3)$ \\
\hline \multicolumn{5}{|l|}{ Lack of control-health } \\
\hline Always (38:168) & $29.6(11.5)^{*}$ & $37.5(13.6)$ & $40.4(14.1)$ & $41.1(13.2)$ \\
\hline Often $(62: 259)$ & $36.1(11.2) \dagger$ & $39.0(11.6)$ & 44.0 (11.5) & 44.9 (11.5) \\
\hline Sometimes (196:1152) & $42.1(12.2) \dagger$ & 45.5 (11.0) & $49.3(10.8)$ & $49.3(10.2)$ \\
\hline Rarely $(131: 1070)$ & $47.3(9.9)$ & $49.8(8.6)$ & $51.7(8.7)$ & $51.3(8.5)$ \\
\hline Never (426:3944) & $50.0(8.9)$ & $52.2(7.3)$ & $53.3(7.8)$ & $54.4(7.1)$ \\
\hline \multicolumn{5}{|l|}{ Lack of control-finances } \\
\hline Always (53:386) & $44.7(11.2) \dagger$ & $48.0(10.6)$ & $43.5(9.9)$ & 43.5 (12.8) \\
\hline Often $(90: 499)$ & $49.7(10.7)$ & $49.7(9.7)$ & 45.7 (10.9) & $46.9(10.5)$ \\
\hline Sometimes (186:1617) & $46.8(10.3) \dagger$ & $50.7(8.9)$ & $51.5(8.8)$ & $51.1(8.3)$ \\
\hline Rarely $(149: 1147)$ & $47.8(10.1)$ & $51.3(8.8)$ & $53.5(7.7)$ & $51.3(8.5)$ \\
\hline Never (389:3825) & $47.7(11.6)$ & $49.6(9.5)$ & $51.8(9.4)$ & $54.2(7.7)$ \\
\hline \multicolumn{5}{|l|}{ Lack of control-personal life } \\
\hline Always (23:77) & $44.8(14.7) \dagger$ & $48.1(11.4)$ & 41.9 (15.7) & $38.2(14.6)$ \\
\hline Often (31:184) & $48.2(14.2)$ & 46.1 (12.5) & 35.5 (10.4) & $37.3(11.7)$ \\
\hline Sometimes (169:1051) & $47.5(11.1)$ & $50.2(9.6)$ & $45.6(10.5)$ & $47.5(9.8)$ \\
\hline Rarely (179:1243) & $44.8(9.4)^{*}$ & $50.8(8.6)$ & $50.3(9.1)$ & $50.9(7.9)$ \\
\hline Never (465:4025) & $47.2(11.1)$ & $49.9(9.3)$ & $55.5(6.2)$ & $54.7(6.8)$ \\
\hline
\end{tabular}


Table 6 Linear regression model for the SF-12 physical component summary in subjects with current doctor-diagnosed asthma

\begin{tabular}{llcc}
\hline & \multicolumn{3}{l}{ Standardised coefficient (beta) } \\
\cline { 2 - 4 } & Model 1 & Model 2 & Model 3 \\
\hline Age (per 10 year groups) & $-0.479^{*}$ & $-0.452^{*}$ & $-0.426^{*}$ \\
Family's money situation & $0.129 \dagger$ & $0.095 \ddagger$ & $0.053 \ddagger$ \\
Education level & $0.093^{*}$ & 0.071 & $0.112^{*}$ \\
Days partially unable to work/usual duties & - & $-0.385^{*}$ & $-0.266^{*}$ \\
Feeling of a lack of control with health & - & - & $-0.331^{*}$ \\
$R$ for model & 0.55 & 0.67 & 0.73 \\
\hline${ }^{*} p<0.001 ; \uparrow p<0.01 ; \ddagger p<0.05$. & & & \\
\hline
\end{tabular}

treatment decisions with their doctor show improved outcomes. ${ }^{33}{ }^{34}$ A decreased sense of personal control over health leading to decreased confidence and a diminished desire to manage their treatment may be one mechanism by which a lower sense of self-control may be associated with lower quality of life in people with asthma. A decreased sense of control over the circumstances of asthma is unlikely to increase the desire to control or self-manage asthma treatment. With the increased focus on promoting selfmanagement through activities such as the Australian NAC $3+$ plan, it is uncertain whether those at most risk for poor outcomes require programmes specifically designed to improve perceived control before any effective self-management education can occur. ${ }^{35}$

An awareness of psychological factors can influence clinical practice. Bukstein ${ }^{36}$ has reported that the use of a point of care "asthma report card" led to an increased number of psychiatric referrals. He noted that, in asthma patients who had stable clinical markers but who reported feeling that their asthma was "really bad and my energy is down", physicians learned to look for depression. Kolbe et al have shown strong associations between behaviour, outcomes, and a positive response to a simple query regarding previous emotional counselling. ${ }^{35}$ De Araujo et al found that asthma patients with greater psychosocial assets required lower doses of corticosteroids. ${ }^{37}$ If a limited number of items measuring psychosocial distress ${ }^{38}$ can be integrated into routine care, this may contribute to better asthma management. ${ }^{39}$

Because of the cross sectional nature of our study, we were unable to determine a causal relation between asthma, psychological distress, perceived lack of control, and impaired quality of life. We were also unable to examine the relationship between differing levels of asthma severity and psychological factors as data on clinical variables were not collected. Our study was also limited by relying on selfreports of a doctor's diagnosis of asthma. People are more likely to report respiratory symptoms if they have an abnormal psychological condition such as anxiety or depression. ${ }^{40}$ It is possible that, in some cases, the doctor could also be misguided in the diagnosis of asthma because of the presence of anxiety or depression.

One difficulty with research examining depression in conditions such as asthma is that survey instruments often contain items that can be affected by physical illness rather than mood states. $^{39}$ Sleep disturbance, for example, is common in asthma, particularly as severity increases. ${ }^{41}$ The K10 does not contain items specifically related to sleep disturbance or fatigue, so the association is less likely to be confounded by misclassification between asthma and psychological symptoms. Because of the wide variety of adverse psychological factors that may be operational in asthma, an assessment of the overall psychological burden, such as via the K10, may be more appropriate. This may also be reflected in the assessment of life events or "catch all" assessments such as "previous emotional counselling" reported by previous authors. ${ }^{6}$

The reporting of respiratory symptoms in general populations may also be influenced by psychological status. ${ }^{42}$ Macleod et al have shown, in relation to cardiovascular disease, that reporting bias can generate associations between self-reported exposures and outcomes in that those who felt greater stress reported more symptoms but did not have increased mortality or rates of myocardial infarction. ${ }^{43}$ These authors also suggested that residual confounding by unmeasured socioeconomic factors might be sufficient to explain the associations. ${ }^{43}$ The measure used in that study was an old measure of an imprecise and ill defined concept of "stress" ${ }^{44}$ Others using more contemporary instruments have found links between psychological factors and objectively measured health outcomes. ${ }^{45}$ However, this may explain why, in the multivariate models which controlled for sociodemographic variables, psychological distress is not significantly associated with PCS scores. Further research is needed to examine the link between asthma symptoms, morbidity, lung function measurements, and psychological factors including depression, anxiety, perceived control, and coping styles. This will require a large population based study with biomedical data as well as appropriate psychosocial questionnaires. The effect of psychological factors on the performance of specific components of asthma self-management tasks and the way in which clinicians may influence this also require further research.

These results, from a representative population sample, show that psychological distress and decreased feelings of control are common in asthma and have a significant association with physical health. This has considerable implications for asthma management and clinical guidelines. A greater focus on anxiety, depression, and perceptions of control seems justified as central to asthma management. Conversely, clinicians responsible for managing people with mental health problems need to be aware of the potential adverse impact of physical illnesses such as asthma.

\section{Authors' affiliations}

R J Adams, D H Wilson, R E Ruffin, The Health Observatory, The Queen Elizabeth Hospital Campus, University of Adelaide, South Australia A W Taylor, E Dal Grande, Population Research and Outcome Studies Unit, Department of Human Services, South Australia

A Daly, Department of Health, Western Australia

E Tursan d'Espaignet, Centre for Child Health Research, University of Western Australia, Telethon Institute for Child Health Research, Western Australia

\section{REFERENCES}

1 Janson-Bjerklie S, Ferketich S, Benner $P$, et al. Clinical markers of asthma severity and risk: importance of subjective as well as objective factors. HeartLung 1992;21:265-72. 
2 O'Connor GT, Weiss ST. Clinical and symptom measures. Am J Respir Crit Care Med 1994;149:S21-8.

3 ten Brinke A, Ouwerkerk ME, Zwinderman AH, et al. Psycholopathology in patients with severe asthma is associated with increased health care utilization. Am J Respir Crit Care Med 2001;163:1093-6.

4 Afari N, Schmaling KB, Barnhart S, et al. Psychiatric comorbidity and functional status in adult patients with asthma. J Clin Psychol Med Settings 2001;8:245-52.

5 Campbell DA, Yellowlees PM, McLennan G. Psychiatric and medical features of near fatal asthma. Thorax 1995:50:254-9.

6 Kolbe J, Fitzgerald M, Macklem PT. Near fatal asthma: a New Zealand perspective. Proceedings of a workshop on near fatal asthma, Montreal, April 1994. Can Respir J 1995;2:113-26.

7 Bussing R, Burket RC, Kelleher ET. Prevalence of anxiety disorders in a clinicbased sample of pediatric asthma patients. Psychosomatics 1996;37:108-15.

8 Shavitt RG, Gentil V, Mandetta R. The association of panic/agoraphobia and asthma: contributing factors and clinical implications. Gen Hosp Psychiatry 1992;14:420-3.

9 Janson C, Bjornsson E, Hetta J, et al. Anxiety and depression in relation to respiratory symptoms and asthma. Am J Respir Crit Care Med 1994; 149:930-4.

10 Kaptein AA. Psychological correlates of length of hospitalisation and rehospitalisation in patients with acute, severe asthma. Soc Sci Med 1982;16:725-9.

11 Ware JE, Kosinski M, Keller SD. SF-36 physical and mental health summary scales: a user's manual. Boston, MA: The Health Institute, New England Medical Center, 1994.

12 Green LW, Frankish CJ. Theories and principles of health education applied to asthma. Chest 1994;106:219-30S.

13 Bandura A. Self efficacy mechanism in human agency. Am Psychol 1982;37:122-47.

14 Apter AJ, Reisine ST, Affleck G, et al. Adherence with twice-daily dosing of inhaled steroids. Am J Respir Crit Care Med 1998;157:1810-7.

15 Clark NM, Rosenstock IM, Hassan H, et al. The effect of health beliefs and feelings of self efficacy on self management behaviour of children with a chronic disease. Patient Educ Counsel 1988;11:131-9.

16 Katz PP, Yelin EH, Eisner MD, et al. Perceived control of asthma and quality of life among adults with asthma. Ann Allergy Asthma Immunol 2002;89:251-8.

17 Information and Research Branch, Department of Health and Aged Care and the National Key Centre for Social Applications of Geographical Information Systems GISCA University of Adelaide. Measuring remoteness: Accessibility/Remoteness Index of Australia (ARIA). Department of Health and Aged Care Occasional Papers Series New No. 6. 2002:2-7-2.

18 Kessler RC, Mroczek D. Final versions of our non-specific psychological distress scale. Institute for Social Research, Survey Research Center, The University of Michigan, 1994.

19 Anon. K10 symptom scale. Clinical Research Unit for Anxiety and Depression, a WHO Collaborating Center, School of Psychiatry, University of NSW, 2000.

20 Anon. Using the $\mathrm{K} 10$ to measure psychological distress. The health of the people of NSW: Report of the Chief Health Officer. Sydney: Epidemiology and Surveillance Branch, NSW Health Department, 2001.

21 Andrews G, Slade T. Interpreting scores on the Kessler psychological distress scale (K10). Aust NZ J Public Health 2001;25:494-7.

22 Ware JE Jr, Kosinski M, Keller SD. A 12-item Short Form Health Survey: construction of scales and preliminary tests of reliability and validity. Med Care 1996;34:220-33.
23 McCallum J. The SF-36 in an Australian sample: validation. Aust J Public Health 1995; 19:166.

24 Taylor A, Daly A, d'Espaignet E, et al. Collaborative Health and Wellbeing Survey. CATI survey of adults living in Western Australia, Northern Territory and South Australia: Report 1: Summary of results by state/territory. South Australian Department of Human Services, 2002.

25 Ware J, Snow K, Kosinski M, et al. SF-36 health survey: manual and interpretanon guide. Boston, Massachusetts: The Health Institute, New England Medical Center, 1993.

26 Silberman EK, Weingartner H, Post RM. Thinking disorder in depression. Arch Gen Psychiatry 1983;40:775-80.

27 Tarbuck AF, Paykel ES. Effects of depression on the cognitive function of young and older subjects. Psychol Med 1995;25:285-95.

28 Paykel ES, Michael A, Sahakian BJ. Cognitive impairment in remission of bipolar affective disorders. Psychol Med 2000;30:1025-36.

29 Lemelin S, Baruch P, Vincent A, et al. Attention disturbance in clinical depression. Deficient distraction inhibition or processing resource deficit. J Nerv Ment Dis 1996;184:114-21.

30 Kolbe J, Vamos M, Fergusson W, et al. Determinants of management errors in acute severe asthma. Thorax 1998;53:14-20.

31 Lehrer PM, Feldman J, Giardino N, et al. Psychological aspects of asthma. J Consult Clin Psychol 2002;70:691-711.

32 Kinsman RA, Dirks JF, Jones NF, et al. Anxiety reduction in asthma: four catches to general application. Psychosom Med 1980;42:397-405.

33 Greenfield S, Kaplan SH, Ware J Jr, et al. Patients' participation in medical care: effects on blood sugar control and quality of life in diabetes. J Gen Intern Med 1988;3:448-57.

34 Bonner S, Rivera R, Zimmermann BJ. Improving asthma management by focusing on families' self-regulatory phase. Am J Respir Crit Care Med 1997; 155:A728.

35 Kolbe J, Vamos $M$, Fergusson W, et al. Differential influences on asthma selfmanagement knowledge and self-management behaviour in acute severe asthma. Chest 1996;110:1463-8.

36 Bukstein DA. Practical approach to the use of outcomes in asthma. Immunol Allergy Clin North Am 1996;16:859-91.

37 De Araujo G, Van Arsdel PP, Holmes TH, et al. Life change, coping ability and chronic intrinsic asthma. J Psychosom Res 1973;17:359-63.

38 Spitzer RL, Kroenke K, Williams JB. Validation and utility of a self-report version of the PRIME-MD: the PHQ primary care study. JAMA 1999;282:1737-44

39 Wolfe F. Practical issues in psychosocial measures. J Rheumatol 1997:24:990-3.

40 Rimmington LD, Davies DH, Lowe $D$, et al. Relationship between anxiety, depression, and morbidity in adult asthma patients. Thorax 2001;56:226-31.

41 Colice GL, Vanden Burgt L, Song J, et al. Categorizing asthma severity. Am J Respir Crit Care Med 1999; 160:1962-7.

42 Dales RE, Spitzer WO, Schechter MT, et al. The influence of psychological status on respiratory symptom reporting. Am Rev Respir Dis 1989;139:1459-63.

43 Macleod J, Smith GD, Heslop P, et al. Psychological stress and cardiovascular disease: empirical demonstration of bias in a prospective observational study of Scottish men. BMJ 2002;324:1247.

44 Lynch J. Psychosocial factors and health: strengthening the evidence base. BMJ 2002;324:1247.

45 Iribarren C, Sidney S, Bild DE, et al. Association of hostility with coronary artery calcification in young adults: the CARDIA study. JAMA 2000;283:2546-51. 